\title{
THE USE OF SPECIES DISTRIBUTION MODELLING AND LANDSCAPE GENETICS FOR TSETSE CONTROL
}

\author{
M. T. BAKHOUM ${ }^{1}$, M. J. B. VREYSEN ${ }^{1}$ AND J. BOUYER ${ }^{1,2,3}$ \\ ${ }^{1}$ Insect Pest Control Laboratory, Joint FAO/IAEA Division of Nuclear Techniques in \\ Food and Agriculture, Vienna, Austria; J.Bouyer@iaea.org \\ ${ }^{2}$ Unité Mixte de Recherche ASTRE 'Animal, Santé, Territoires, Risques et \\ Ecosystèmes', Campus International de Baillarguet, Centre de Coopération \\ Internationale en Recherche Agronomique pour le Développement (CIRAD), \\ Montpellier, France \\ ${ }^{3}$ Intertryp, IRD, CIRAD, Université de Montpellier, Montpellier, France
}

\begin{abstract}
SUMMARY
Trypanosomosis is one of the major constraints to rural development in sub-Saharan Africa. Studies of the species distribution and landscape genetics allows for targeting tsetse-infested areas and optimizing the management of tsetse fly populations. In this chapter, a review is provided on 1) available spatial tools and landscape genetics, 2) the use of tsetse distribution models to rank populations according to their level of isolation to assist identifying populations that can be targeted for eradication, and 3) the use of tsetse distribution models to optimize tsetse control efforts within an area-wide integrated pest management context.

Key Words: Glossina, habitat suitability, African trypanosomosis, nagana, sleeping sickness, sub-Saharan Africa, area-wide integrated pest management, spatial modelling, Maxent, distribution models, friction models, population genetics
\end{abstract}

\section{INTRODUCTION - THE TSETSE AND TRYPANOSOMOSIS PROBLEM}

Tsetse flies (Glossina spp.) are widely distributed in sub-Saharan Africa and inhabit semi-arid, sub-humid and humid lowlands in 37 countries across the continent with a potential distribution range of some 8.7 million $\mathrm{km}^{2}$ (Rogers and Robinson 2004). They transmit trypanosomes, the causative agents of sleeping sickness (human African trypanosomosis, HAT) and nagana (African animal trypanosomosis, AAT). 
Together, the animal and human diseases pose health threats and a great economic burden to vast regions of sub-Saharan Africa where they are endemic (Swallow 1999; Diall et al. 2017).

The number of HAT cases has substantially declined in the last 15 years, mainly through increased disease surveillance and treatment of affected patients (WHO 2013), and since 2012 in Trypanosoma brucei gambiense HAT foci, thanks to increased vector control (Courtin et al. 2015; Mahamat et al. 2017). Whereas in 2000 there were more than 25000 newly reported cases, this had decreased to 7106 new cases by 2012. In 2018, less than 1000 new cases of HAT were reported to the World Health Organization (WHO 2019), which represents the lowest number of sleeping sickness cases ever recorded. In some countries with ongoing conflicts, there is obviously the likelihood of under-reporting of cases. There is, however, general consensus that the complete elimination of HAT as a public health problem can only be possible through the inclusion of an effective vector management component (Solano et al. 2013; Feldmann et al. 2021).

Contrary to the advances made with the management of HAT, the AAT continues to represent the greatest animal health constraint to improved livestock production in sub-Saharan Africa, causing economic losses amounting to USD 4.75 billion annually and putting approximately 50 million cattle at risk (i.e. milk and meat production) (Swallow 1999; Scoones 2016). The disease also prevents the integration of crop farming and livestock keeping, a crucial component for the development of sustainable agricultural systems (Alsan 2015).

Early death can result in chronically infected animals if AAT is not treated, and at least three million cattle and other domestic animals succumb to the disease each year (Hursey and Slingenbergh 1995). When not lethal, AAT brings livestock into a chronically debilitating condition and reduces fertility, weight gain, meat and milk production by at least $50 \%$, as well as the work efficiency of oxen used to cultivate the land (Budd 1999; Swallow 1999; Shaw 2004). The disease has also indirect negative effects on the development of commercial domestic and livestock production, i.e. it discourages the use of more-productive exotic and cross-bred cattle, depresses the growth and distribution of livestock populations, reduces the potential opportunities for integration of livestock keeping and crop production through less draught power to cultivate land and to transport farm products to market, and less manure to fertilize (in an environment-friendly way) soils for better crop production.

In addition, the scarcity of domestic animals leads to a serious shortage of animal protein for human consumption and as people tend to avoid areas infested with tsetse flies, they affect human settlement (Shaw 2004). Consequently, tsetse flies and the AAT it transmits are considered as one of the root causes of hunger and poverty in about one third of the African continent (Feldmann et al. 2021). AAT therefore is an important limiting factor to reach Sustainable Development Goals 1 (No Poverty) and 2 (Zero Hunger) (UN 2019).

Understanding the distribution of tsetse flies in space and time is essential in selecting the most appropriate intervention strategies for the area-wide management of tsetse populations in different parts of sub-Saharan Africa. Despite substantial efforts for more than a century, deliberate efforts to reduce the vast tsetse belt have had very limited success (Vreysen et al. 2013). 
In past decades, spraying of insecticides was effective in controlling tsetse fly populations in certain areas of the African continent, e.g. to stop the advancing front of tsetse flies in south-eastern Zimbabwe and south-western Mozambique between 1962 and 1974 (Robertson and Kluge 1968; Lovemore 1972, 1973, 1974; Robertson et al. 1972), and to eliminate tsetse flies in Zimbabwe (Jordan 1986), Nigeria (MacLennan and Kirby 1958), Botswana (Davies 1980), Zambia (Paynter and Brady 1992), the Zambezi region (formerly Caprivi Strip) of Namibia, and in Malawi (Vale 1999). However, although the spraying of non-residual pyrethroids as ultra-low volume formulations either using ground fogging techniques or the sequential aerosol technique (SAT) was until recently still used in Burkina Faso, Ethiopia, Ghana, Guinea and Zimbabwe (Bouyer and Vreysen 2018), the spraying of residual insecticides is no longer recommended anymore on environmental grounds.

Whereas in the past, suppression methods were often used alone and against only certain segments of the tsetse population, in the last decades it has become evident that more sustainable tsetse population management can be obtained when applying two compatible strategies, i.e. area-wide integrated pest management (AW-IPM) (Vreysen et al. 2007) and the phased conditional approach (PCA) (Bouyer and Vreysen 2018). The management of tsetse fly populations can be implemented using two basic approaches, i.e. on a localised field-by-field basis or on an area-wide basis (total population management) (AW-IPM) (Hendrichs et al. 2007; Klassen and Vreysen 2021). AW-IPM is an approach that consists of a coordinated effort against all sub-units of a target pest population in an ecosystem before the pest population has reached damaging proportions. Local field-by-field pest control is a reactive effort when the pest population reaches damaging levels and is carried out individually and independent of the action of neighbouring farmers. These two strategies have different objectives. Whereas population suppression (the reduction of the insect pest density below a threshold preventing damage or disease transmission) can be the objective in both cases, local population elimination (eradication would signify the elimination of all populations of a given insect species from the planet) is only possible using the second approach, with higher costs but proportional longer-term impacts (Vreysen 2006; Bouyer et al. 2013).

The AW-IPM approach minimizes the risk of reinvasion, as areas that are of no interest to the farmers are also targeted. This approach usually requires several years of planning and a specialised organization with dedicated staff to implement the control activities, in an adaptive management scheme. The AW-IPM can benefit from advanced technologies such as geographic information systems (GIS), population genetics (increasingly being used for designing and implementing tsetse control efforts; Bouyer et al. 2021), remote sensing and aerial dissemination techniques (Vreysen 2006; Dicko et al. 2014; Klassen and Vreysen 2021).

This chapter highlights the integration of species distribution modelling and landscape genetics to facilitate the management of tsetse populations. First, it presents a general overview of spatial tools and landscape genetics. Second, it presents how modelling the distribution of tsetse populations and ranking them according to their level of isolation can help to identify populations that can be targeted for eradication. Finally, it presents how tsetse distribution models can be used to optimize tsetse control efforts within an AW-IPM context. 


\section{GENERAL OVERVIEW OF SPATIAL TOOLS AND LANDSCAPE GENETICS}

\subsection{Spatial Modelling and Geographic Information Systems}

Spatial tools have long been important to natural resource applications. The GIS, global positioning system (GPS), and remote sensing (RS) are spatial tools that have become more and more important for decision-making in the control of diseases, i.e. to locate important target sites, to predict population change based on climatic trends, to report potential anomalies, but also to analyse landscape patterns, disaster management, etc. Data can, in many instances, only be fully understood when they can be placed in a geographic context. Hence the benefits that can be derived from using GIS, which are computer-based tools that analyse, store, manipulate and visualize geographic information, usually in a map (Bouyer et al. 2021). GPS is a satellite navigation system used to determine the exact position of an object, whereas $\mathrm{RS}$ aims at providing access to a range of satellite-derived data products about the earth's surface using electromagnetic sensors.

These geospatial tools have made the design and the implementation of AW-IPM programmes and disease control much more effective and cost-efficient. The importance of geomatic tools to assist various stages of planning and application of the Sterile Insect Technique (SIT) as part of an AW-IPM approach is presented elsewhere (Bouyer et al. 2021) and includes the selection of project sites, planning of pre-intervention surveys and feasibility assessments before the start of the operational implementation campaign. Geomatic tools are also essential to monitor and analyse insect populations during area-wide control efforts to be able to implement adaptive management (Vreysen et al. 2013).

\subsection{Landscape Genetics Approach}

Landscape genetics, that associates tsetse population genetics with spatial tools, is an innovative and emerging approach that enables understanding how geographic and environmental features structure genetic variation at the population and individual scales (Feldmann and Ready 2014). Genetic markers with varying temporal or spatial resolution can be used to implement landscape genetics, depending on ecological questions (De Meeûs et al. 2007). This approach can not only be used for improving ecological knowledge, but also for explaining observed spatial genetic patterns as clines, isolation by distance, genetic boundaries to gene flow, metapopulations and random patterns (Manel et al. 2003), in order to manage properly the genetic diversity.

Various approaches have been used to quantify the spatial structure relying on landscape ecology. However, most involve the incorporation of the notion of landscape resistance or friction (i.e. the impediments to gene flow) caused by landscape features. The most common approach employed involves measuring the "cost" distance between populations sampled based on one or more alternative landscape resistance models (Manel et al. 2003).

Informing on the resistance of landscape to movement is essential to refine species distribution models. The geographic distribution of a given species can be seen as the 
intersection between biotic (B), abiotic (A) and movement (M) factors in a BAM diagram (Soberón and Peterson 2005). However, most species distribution models neglect the latter (Barve et al. 2011), often because they are based on presence/absence data and rarely include genetic data. It is however essential to account for movement, as a given landscape can be suitable for a given species, but not inhabited because it is out of reach for this species. Moreover, friction should not be mapped based on expert knowledge, as this is very subjective and therefore essentially unpredictable.

Tsetse studies have demonstrated that the environmental parameters driving landscape suitability are totally different from those driving landscape friction (Bouyer et al. 2015). This can be described as the "salamander paradox", i.e. if a forest salamander finds itself at $100 \mathrm{~m}$ from the edge of a forest, in an area where the ground is bare and very inhospitable to its survival, it will either die quickly or move as fast as possible to the forest. Conversely, if the salamander finds itself in the forest, it will be in a location with all suitable conditions and it will not disperse much. Therefore, the friction of the forest will be higher than that of the bare ground, which seems counter-intuitive (Peterman et al. 2014).

Insect pest populations can be structured at micro-geographic scales, which must be accounted for to optimize control. For example, the inclusion of population genetics data in control programmes against tsetse populations of the palpalis group in West Africa provided information on the level of genetic isolation of the target populations from the neighbouring ones, which allowed informed decisions for developing control strategies. However, for population genetic tools to provide accurate inferences, individuals must be sampled at the smallest scale possible and the molecular markers carefully selected (Solano et al. 2010a).

\section{APPLICATION OF DISTRIBUTION MODELS AND LANDSCAPE GENETICS FOR TSETSE CONTROL}

\subsection{Mapping Landscape to Identify Isolated Tsetse Populations}

Understanding how geographic and environmental features structure genetic variation of tsetse populations is essential for the development of intervention strategies of these cyclical vectors of HAT and AAT in sub-Saharan Africa. Evidence of restricted or absence of gene flow allows genetically isolated islands to be identified (Solano et al. 2009), or isolated ecological population islands (Solano et al. 2010b), from where the tsetse populations present could be eradicated without risk of reinvasion.

For example, two environment-friendly tsetse eradication campaigns achieved the creation of a sustainable tsetse-free zone, i.e. (1) on the Island of Unguja, Zanzibar where an AW-IPM strategy was used to sustainably remove an isolated population of Glossina austeni Newstead using the integration of insecticide-impregnated screens, insecticide pour-on on livestock and the SIT (Vreysen et al. 2000), and (2) in the Okavango Delta of Botswana, where an isolated population of Glossina morsitans centralis (Machado) was sustainably removed using the SAT in combination with traps and targets in the barrier zones (Vreysen et al. 2000; Kgori et al. 2006). 
Recently, landscape genetics has established itself as an important area of research/investigation in the field of tsetse fly control (Bouyer et al. 2015; Bouyer and Lancelot 2018; Saarman et al. 2018). This has allowed the identification of potentially isolated tsetse populations, which offers the opportunity of:

1) selecting the most appropriate intervention strategies for stage 1 of the progressive control pathway (PCP) for AAT (Diall et al. 2017), a stepwise approach leading to their reduction, elimination and finally, vector eradication,

2) planning an integrated management approach (stage 2 of the PCP), and

3 ) the choice of suppression and elimination activities (stages 3 and 4 of the PCP).

Bouyer et al. (2015) developed a friction map between 37 populations of Glossina palpalis gambiensis (Robineau-Desvoidy) in different areas of West Africa by iterating linear regression models of genetic distance between the populations and environmental data as predictors and by determining least-cost dispersal paths. The effect of environmental factors on genetic distance was studied using a linear regression model to estimate the relationship between genetic distance and a set of environmental factors. The main variables influencing genetic distance were:

1) the geographic distance,

2) being located within the same river basin or not, and

3) three metrics of habitat fragmentation, namely the patch density, the surface of suitable area, and the maximum distance between the habitat patches (Bouyer et al. 2015).

A density-based clustering algorithm, applied to the Maxent open-source software output (Phillips et al. 2019), identified eight potentially isolated clusters of suitable habitats containing tsetse populations that were located at least $10 \mathrm{~km}$ away from the main tsetse belt (Fig. 1) (Bouyer et al. 2015). This is essential for selecting potential target areas that contain isolated tsetse fly populations that could potentially be eradicated in a sustainable way.

Moreover, the population with the highest predicted genetic distance from the main tsetse belt $(\mathrm{P}=0.003)$ was located in the Niayes area of Senegal and is the target of an ongoing eradication campaign (Vreysen et al., this volume).

In line with Bouyer et al. (2015)'s approach for identifying isolated tsetse populations, Saarman et al. (2018) developed methods to create a connectivity surface to identify isolated habitat areas reflecting the genetic and ecological connectivity at a spatial scale of interest. By integrating genetic data from 38 samples, remotely sensed environmental data, and hundreds of field-survey observations from northern Uganda, the approach of Saarman et al. allowed the identification of isolated habitat of Glossina fuscipes fuscipes Newstead. To identify isolated habitats, the methodological framework (1) first identifies environmental parameters in correlation with genetic differentiation, (2) predicts spatial connectivity using field-survey observations and the most predictive important environmental parameter(s), and (3) overlays the connectivity surface onto a habitat suitability map (Saarman et al. 2018). 


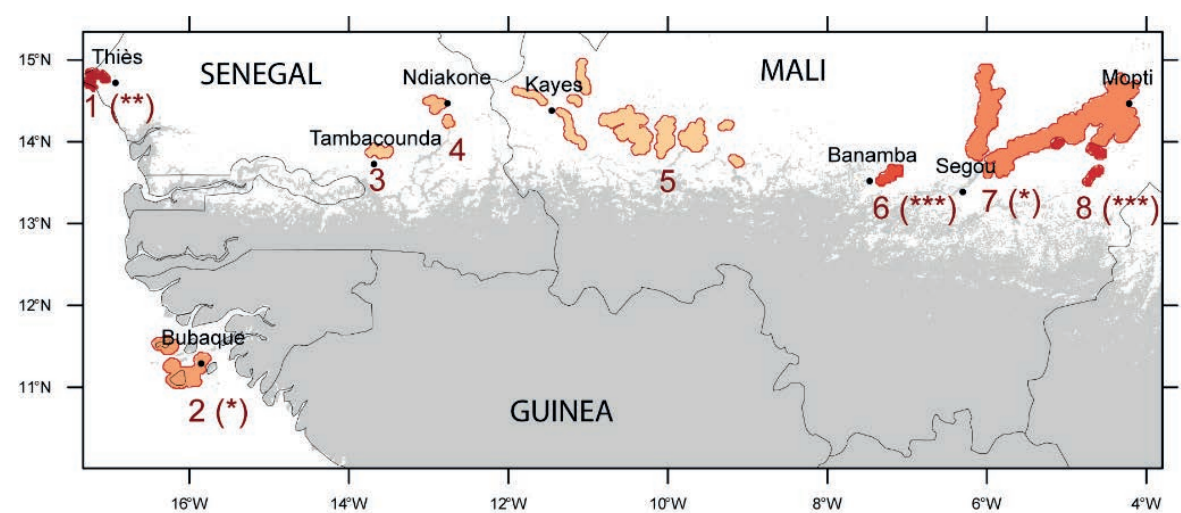

Genetic distance from habitat patches to the main tsetse habitat

\begin{tabular}{|c|c|c|c|}
\hline Cluster $1(0.27)$ & Cluster $3(0.32)$ & Cluster $5(0.35)$ & Cluster $7(0.38)$ \\
\hline Cluster $2(0.30)$ & Cluster $4(0.33)$ & Cluster $6(0.37)$ & Cluster 8 (0.39) \\
\hline
\end{tabular}

Figure 1. Identification of 8 isolated populations of Glossina palpalis gambiensis in West Africa. The main tsetse belt predicted by Maxent ${ }^{1}$ for a sensitivity of 0.90 is in grey and habitat patches are shown as filled, red shapes. Contours and shapes of isolated patches were defined as 5-km radius buffers around pixels of habitat patches. The genetic distance of these patches to the main tsetse belt (reddish scale) was predicted by the AICc-best regression model along least-cost paths. Star symbols after cluster numbers represent the p values for the friction between the patches and the general habitat: (***) $p=10-3$, (**) $10-3 \leq p<$ 10-2, (*) 10-2 $\leq p<5$ 10-2 (modified from Bouyer et al. 2015).

${ }^{1}$ The open-source Maxent software is based on the maximum-entropy approach for modelling species niches and distributions (Phillips et al. 2019).

The results from this approach indicate that net photosynthesis is the most powerful predictor of genetic differentiation for $G$. f. fuscipes in northern Uganda. Of the 40 distinct landscape patches of adequate size and distance (purple outlines in Fig. $2 \mathrm{a})$, the resulting connectivity area identified a large, well-connected habitat area in north-western Uganda, as well as 24 plots that contained habitat that was for $>25 \%$ considered suitable for G. f. fuscipes according to the model (purple outlines in Fig. $2 b$ ). These 24 isolated plots were selected as possible candidates to locally create tsetse-free zones and / or testing of new control methods or approaches.

Landscape genetics may also be used to locate areas of high friction where barriers to tsetse dispersal such as insecticide targets or traps are more likely to isolate the target areas.

\subsection{Tsetse Distribution Models to Optimize Vector Control}

Tsetse distribution models are not only used to map the risk of AAT (Dicko et al. 2015) but are also very useful to optimize tsetse control operations. These models are very useful for selecting priority intervention areas and guiding the management of the vector control operations during all stages of the PCP for addressing AAT (Diall et al. 2017). For example, these models were applied in pilot studies of tsetse control targeting one riverine tsetse species, G. palpalis gambiensis in the Niayes area in 
Senegal (Dicko et al. 2014), and two savannah species, G. morsitans morsitans Westwood and $G$. pallidipes Austin in the Masoka area, mid-Zambezi valley in Zimbabwe (Chikowere et al. 2017).
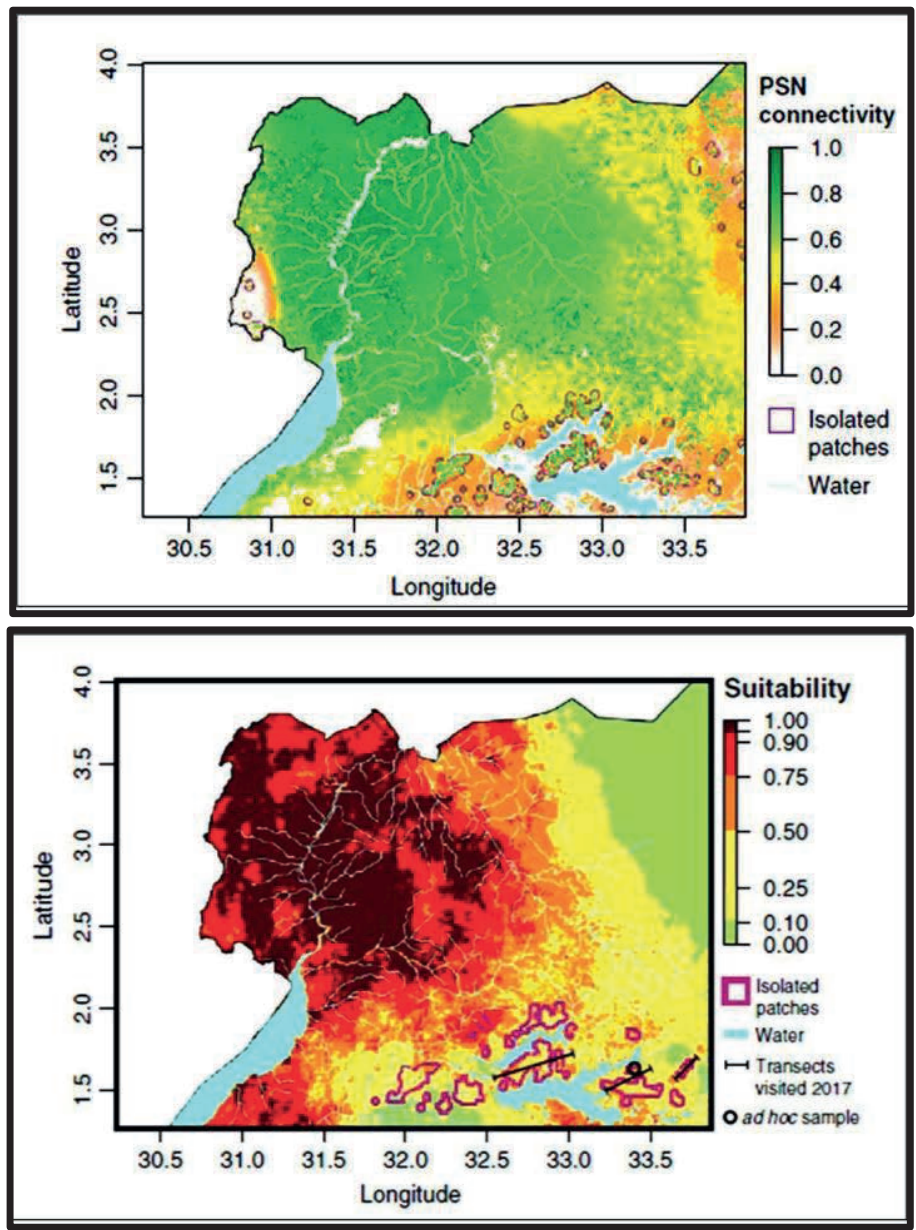

Figure 2 a (top). Location of discrete isolated patches in purple and identification of 24 isolated patches of Glossina fuscipes fuscipes in northern Uganda. A Maxent model was used to produce a connectivity surface, using the environmental variables significantly correlated with genetic differentiation from the previous step and field-survey presence data from 317 traps from northern Uganda.

Figure $2 b$ (bottom). Habitat suitable for Glossina fuscipes fuscipes predicted by updating the habitat suitability map obtained with 317 presence data and 12 environmental variables relevant to tsetse ecology by Maxent model. Twenty-four isolated patches identified by the model (purple polygons), the three transects (black lines) used for the field survey, and the location of the tsetse sample from one of the isolated patches used to validate the method (modified from Saarman et al. 2018). 
Using a regularized logistic regression and Maxent, Dicko et al. (2014) compared the probability of presence of G. palpalis gambiensis and habitat suitability, respectively. The nature of predictions differed between regularized logistic regression (probability) and Maxent (index). The result provided a better understanding of the relationship between tsetse presence and various environmental parameters as measured by RS. Maxent predicted very well suitable areas considered the most important for an eradication objective, based on an expert-based landscape classification, as some suitable patches can be unoccupied at a certain time and colonized later (Peck 2012), but must nevertheless be included in the target area when applying an AW-IPM strategy (Cecilia et al. 2019).

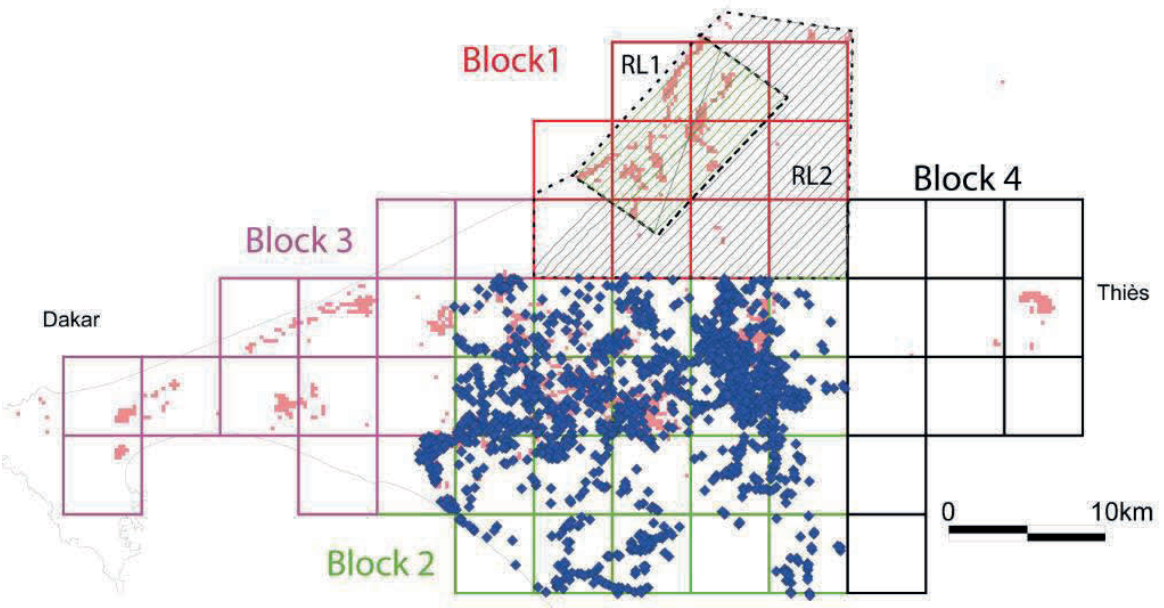

Figure 3. Optimization of the integrated control strategy using model predictions. Maxent model was used to predict the suitable habitats for Glossina palpalis gambiensis in Senegal. In block 1, the suitable habitats allowed to delimitate two polygons for aerial releases (RL1 and RL2) where the number of sterile males released per $\mathrm{km}^{2}$ was adapted to the availability of suitable habitat based on Maxent predictions. In block 1, the green and grey lines present the track flying records of aerial releases on 14th April 2014 in RL1 and 11th April 2014 in

$R L 2$ respectively. In block 2, 1,347 insecticide-impregnated traps were deployed from December 2012 to February 2013 in the predicted suitable sites (blue diamonds) to suppress the Glossina palpalis gambiensis populations (modified from Dicko et al. 2014).

Maxent predictions were used throughout the eradication campaign in the Niayes area of Senegal to make the entire operation more efficient in terms of deployment of insecticide-treated targets, release density of sterile males, and the selection of sites to deploy the monitoring traps used for programme evaluation (Fig. 3). Thereby, Maxent predictions allowed optimizing efficiency and reducing the cost of the eradication campaign. 


\section{CONCLUSIONS}

Species distribution modelling and landscape genetics are crucial for planning and optimizing tsetse fly control programmes, especially when sustainable eradication is the selected strategy. Potentially isolated clusters of tsetse fly habitats were identified based on species distribution models and ranked according to their predicted genetic distance to the main tsetse population to locate potential target populations for eradication.

Integrating distribution models and genetic studies in feasibility studies for control operations may also be useful to apply the PCP for controlling AAT, a stepwise approach leading to the suppression, elimination and eradication of vector populations and disease (Diall et al. 2017). Furthermore, distribution models can help improve the efficiency of control activities, leading to a reduction in costs. Finally, these distribution modelling and landscape genetics approaches should be integrated in the future, not only into tsetse control efforts, but might also help in the area-wide management of other pests as well.

\section{REFERENCES}

Alsan, M. 2015. The effect of the tsetse fly on African development. American Economic Review 105: $382-410$.

Barve, N., V. Barve, A. Jiménez-Valverde, A. Lira-Noriega, S. P. Maher, A. T. Peterson, J. Soberón, and F. Villalobos. 2011. The crucial role of the accessible area in ecological niche modeling and species distribution modeling. Ecological Modelling 222: 1810-1819.

Bouyer, J., and R. Lancelot. 2018. Using genetic data to improve species distribution models. Infection, Genetics and Evolution 63: 292-294.

Bouyer, J., and M. J. B. Vreysen. 2018. Vectors: Tsetse flies, pp. 77. In J. A. W. Coetzer, G. R. Thomson, N. J. Maclachlan, and M.-L. Penrith (eds.), Infectious Diseases of Livestock. Anipedia, J. A. W Coetzer, and P. Oberem (Directors).

Bouyer, F., A. Dicko, M. T. Seck, B. Sall, M. Lo, M. J. B. Vreysen, J. Bouyer, E. Chia, and A. Wane. 2013. A cost-benefit analysis of tsetse eradication in the Niayes area of Senegal. In 32nd ISCTRC Conference, 8-12 September, Khartoum, Soudan.

Bouyer, J., A. Dicko, G. Cecchi, S. Ravel, L. Guerrini, P. Solano, M. J. B. Vreysen, T. De Meeûs, and R. Lancelot. 2015. Mapping landscape friction to locate isolated tsetse populations that are candidates for elimination. Proceedings of the National Academy of Sciences USA 112: 14575-14580.

Bouyer, J., J. S. H. Cox, L. Guerrini, R. Lancelot, A. H. Dicko, J. St. H. Cox, and M. J. B. Vreysen. 2021. Use of geographic information systems and spatial modelling in area-wide integrated pest management programmes that integrate the Sterile Insect Technique, pp. 703-730. In V. A. Dyck, J. Hendrichs, and A. S. Robinson (eds.), Sterile Insect Technique - Principles and practice in Area-Wide Integrated Pest Management. Second Edition. CRC Press, Boca Raton, Florida, USA.

Budd, L. 1999. DFID-funded tsetse and trypanosome research and development since 1980. Volume 2: An economic analysis. DFID Livestock Production Programme. Natural Resources International, Chatham Maritime, UK. 123 pp.

Cecilia, H., S. Arnoux, S. Picault, A. Dicko, M. T. Seck, B. Sall, M. Bassène, M. Vreysen, S. Pagabeleguem, A. Bancé, J. Bouyer, and P. Ezanno. 2019. Environmental heterogeneity drives tsetse fly population dynamics and control. bioRxiv: 493650 (recommended by Peer Community in Ecology).

Chikowere, G., A. Dicko, P. Chinwada, M. Zimba, W. Shereni, F. Roger, J. Bouyer, and L. Guerrini. 2017. A pilot study to delimit tsetse target populations in Zimbabwe. PLoS Neglected Tropical Diseases 11(5): e0005566.

Courtin, F., M. Camara, J. B. Rayaisse, M. Kagbadouno, E. Dama, O. Camara, I. S. Traoré, J. Rouamba, M. Peylhard, M. B. Somda, M. Leno, M. J. Lehane, S. J. Torr, P. Solano, V. Jamonneau, and B. Bucheton. 2015. Reducing human-tsetse contact significantly enhances the 
efficacy of sleeping sickness active screening campaigns: A promising result in the context of elimination. PLoS Neglected Tropical Diseases 9(8): e0003727.

Davies, J. E. 1980. The history of tsetse fly control in Botswana. Report to the Director of Veterinary Services, Botswana.

De Meeûs, T., K. D. McCoy, F. Prugnolle, C. Chevillon, P. Durand, S. Hurtrez-Boussès, and F. Renaud. 2007. Population genetics and molecular epidemiology or how to "débusquer la bête". Infection, Genetics and Evolution 7: 308-332.

Diall, O., G. Cecchi, G. Wanda, R. Argilés-Herrero, M. J. B. Vreysen, G. Cattoli, G. J. Viljoen, R. Mattioli, and J. Bouyer. 2017. Developing a progressive control pathway for African animal trypanosomosis. Trends in Parasitology 33: 499-509.

Dicko, A., R. Lancelot, M. T. Seck, L. Guerrini, B. Sall, M. Lo, M. J. B. Vreysen, T. Lefrançois, W. M. Fonta, S. L. Peck, and J. Bouyer. 2014. Using species distribution models to optimize vector control in the framework of the tsetse eradication campaign in Senegal. Proceedings of the National Academy of Sciences USA 111: 10149-10154.

Dicko, A. H., L. Percoma, A. Sow, Y. Adam, C. Mahama, I. Sidibé, G.-K. Dayo, S. Thévenon, W. Fonta, S. Sanfo, A. Djiteye, E. Salou, V. Djohan, G. Cecchi, and J. Bouyer. 2015. A spatio-temporal model of African animal trypanosomosis risk. PLoS Neglected Tropical Diseases 9 (7): e0003921.

Feldmann, U., and P. D. Ready. 2014. Applying GIS and population genetics for managing livestock insect pests: Case studies of tsetse and screwworm flies. Acta Tropica 138 (Supplement): S1-S5.

Feldmann, U., V. A. Dyck, R. C. Mattioli, J. Jannin, and M. J. B. Vreysen. 2021. Impact of tsetse fly eradication programmes using the sterile insect technique, pp. 1051-1080. In V. A. Dyck, J. Hendrichs, and A. S. Robinson (eds.), Sterile Insect Technique - Principles and practice in Area-Wide Integrated Pest Management. Second Edition. CRC Press, Boca Raton, Florida, USA.

Hendrichs, J., A. S. Robinson, P. Kenmore, and M. J. B. Vreysen. 2007. Area-wide integrated pest management (AW-IPM): Principles, practice and prospects, pp. 3-33. In M. J. B. Vreysen, A. S. Robinson and J. Hendrichs (eds.), Area-wide control of insect pests. From research to field implementation. Springer, Dordrecht, The Netherlands.

Hursey, B. S., and J. Slingenbergh. 1995. The tsetse fly and its effects on agriculture in sub-Saharian Africa. Revue Mondiale de Zootechnie 84: 67-73.

Jordan, A. M. 1986. Trypanosomiasis control and African rural development. Longman Group Ltd., London, UK. pp. 357.

Kgori, P. M., S. Modo, and S. J. Torr. 2006. The use of aerial spraying to eliminate tsetse from the Okavango Delta of Botswana. Acta Tropica 99: 184-199.

Klassen, W., and M. J. B. Vreysen. 2021. Area-wide integrated pest management and the Sterile Insect Technique, pp. 75-112. In V. A. Dyck, J. Hendrichs, and A. S. Robinson (eds.), Sterile Insect Technique - Principles and practice in Area-Wide Integrated Pest Management. Second Edition. CRC Press, Boca Raton, Florida, USA.

Lovemore, D. F. 1972. Annual report of the Branch of Tsetse and Trypanosomiasis Control, Department of Veterinary Services, Ministry of Agriculture, Rhodesia, for the year ended 30th September 1971. Government Printing and Stationery, Salisbury, Rhodesia. 65996-2-300.

Lovemore, D. F. 1973. Annual report of the Branch of Tsetse and Trypanosomiasis Control, Department of Veterinary Services, Ministry of Agriculture, Rhodesia, for the year ended 30th September 1972. Government Printing and Stationery, Salisbury, Rhodesia. 68789-6-300.

Lovemore, D. F. 1974. A note on tsetse and trypanosomiasis control in Rhodesia during the year ended 30th September 1974. Type-written internal report prepared for the Director of Veterinary Services. Salisbury, Rhodesia.

MacLennan, K. J. R., and W. W. Kirby. 1958. The eradication of Glossina morsitans submorsitans Newst. in part of a river flood plain in Northern Nigeria by chemical means. Bulletin of Entomological Research 49: 123-131.

Mahamat, M. H., M. Peka, J. B. Rayaisse, K. S. Rock, M. A. Toko, J. Darnas, G. M. Brahim, A. B. Alkatib, W. Yoni, I. Tirados, F. Courtin, C. Nersy, I. O. Alfaroukh, S. J. Torr, M. J. Lehane, and P. Solano. 2017. Adding tsetse control to medical activities allows a decrease in transmission of sleeping sickness in the Mandoul focus (Chad). PLoS Neglected Tropical Diseases 11(7): e0005792.

Manel, S., M. K. Schwartz, G. Luikart, and P. Taberlet. 2003. Landscape genetics: Combining landscape ecology and population genetics. Trends in Ecology \& Evolution 18: 189-197.

Paynter, Q., and J. Brady. 1992. Flight behaviour of tsetse flies in thick bush (Glossina pallidipes (Diptera: Glossinidae)). Bulletin of Entomological Research 82: 513-516. 
Peck, S. L. 2012. Networks of habitat patches in tsetse fly control: implications of metapopulation structure on assessing local extinction. Ecological Modeling 246: 99-102.

Peterman, W. E., G. M. Connette, R. D. Semlitsch, and L. S. Eggert. 2014. Ecological resistance surfaces predict fine-scale genetic differentiation in a terrestrial woodland salamander. Molecular Ecology 23: 2402-2413.

Phillips, S. J., M. Dudík, R. E. Schapire. 2019. Maxent software for modeling species niches and distributions (Version 3.4.1).

Robertson, A. G., and E. B. Kluge. 1968. The use of insecticide in arresting an advance of Glossina morsitans Westwood in the south-east lowveld of Rhodesia. Proceedings and Transactions of the Rhodesia Scientific Association 53: 17-33.

Robertson, A. G., E. B. Kluge, D. A. Kritzinger, and A. E. De Sousa. 1972. The use of residual insecticides in the reclamation of the Rhodesia- Mozambique border region between the Sabi/Save and Limpopo rivers from Glossina morsitans Westwood. Proceedings and Transactions of the Rhodesia Scientific Association 55: 34-62.

Rogers, D. J., and T. P. Robinson. 2004. Tsetse distribution, pp. 139-179. In I. Maudlin, P. H. Holmes, and M. A. Miles (eds.), The Trypanosomiases. CABI International Wallingford, Oxfordshire, UK.

Saarman, N., M. Burak, R. Opiro, C. Hyseni, R. Echodu, K. Dion, E. A. Opiyo, A. W. Dunn, G. Amatulli, S. Aksoy, and A. Caccone. 2018. A spatial genetics approach to inform vector control of tsetse flies (Glossina fuscipes fuscipes) in Northern Uganda. Ecology and Evolution 8: 5336-5354.

Scoones, I. 2016. Contested histories: Power and politics in trypanosomiasis control, pp. 78-93. In K. Bardosh (ed.), Science, politics and zoonotic disease in Africa, Routledge, New York, USA.

Shaw, A. P. M. 2004. Economics of African trypanosomosis, pp. 369-402. In I. Maudlin, P. H. Holmes, and M. A. Miles (eds.), The Trypanosomiases. CABI Publishing, Wallingford, Oxfordshire, UK.

Soberón, J., and A. T. Peterson. 2005. Interpretation of models of fundamental ecological niches and species' distributional areas. Biodiversity Informatics 2: 1-10.

Solano, P., S. Ravel, and T. De Meeûs. 2010a. How can tsetse population genetics contribute to African trypanosomiasis control? Trends in Parasitology 26: 255-263.

Solano, P., S. J. Torr, and M. J. Lehane. 2013. Is vector control needed to eliminate gambiense human African trypanosomiasis? Frontiers in Cellular and Infection Microbiology 3: 33.

Solano, P., S. Ravel, J. Bouyer, M. Camara, M. S. Kagbadouno, N. Dyer, L. Gardes, D. Herault, M. J. Donnelly, and T. De Meeûs. 2009. The population structure of Glossina palpalis gambiensis from island and continental locations in coastal Guinea. PLoS Neglected Tropical Diseases 3(3): e392.

Solano, P., D. Kaba, S. Ravel, N. A. Dyer, B. Sall, M. J. B. Vreysen, M. T. Seck, H. Darbyshir, L. Gardes, M. J. Donnelly, T. De Meeûs, and J. Bouyer. 2010b. Population genetics as a tool to select tsetse control strategies: Suppression or eradication of Glossina palpalis gambiensis in the Niayes of Senegal. PLoS Neglected Tropical Diseases 4(5): e692.

Swallow, B. M. 1999. Impacts of trypanosomiasis on African agriculture. PAAT Technical and Scientific Series 2. FAO, Rome, Italy. ISSN 1020-7163.

(UN) United Nations. 2019. Sustainable development goals. New York, NY, USA.

Vale, G. A. 1999. Joint tests of insecticides for use on cattle. Final Report. Regional Tsetse and Trypanosomiasis Control Programme, Malawi, Mozambique, Zambia and Zimbabwe. Harare, Zimbabwe.

Vreysen, M. J. B. 2006. Prospects for area-wide integrated control of tsetse flies (Diptera: Glossinidae) and trypanosomosis in sub-Saharan Africa. Revista Sociedad Entomológica Argentina 65 (1-2): 1-21.

Vreysen, M. J. B., A. S. Robinson and J. Hendrichs (eds.). 2007. Area-wide control of insect pests. From research to field implementation. Springer, Dordrecht, The Netherlands. $789 \mathrm{pp}$.

Vreysen, M. J. B., M. T. Seck, B. Sall, and J. Bouyer. 2013. Tsetse flies: Their biology and control using area-wide integrated pest management approaches. Journal of Invertebrate Pathology 112 (Supplement): S15-S25.

Vreysen, M. J. B., K. M. Saleh, M. Y. Ali, A. M. Abdulla, Z. R. Zhu, K. G. Juma, V. A. Dyck, A. R. Msangi, P. A. Mkonyi, and H. U. Feldmann. 2000. Glossina austeni (Diptera: Glossinidae) eradicated on the island of Unguja, Zanzibar, using the sterile insect technique. Journal of Economic Entomology 93: 123-135.

(WHO) World Health Organization \& WHO Expert Committee on the Control and Surveillance of Human African Trypanosomiasis. 2013. Control and surveillance of human African trypanosomiasis: report of a WHO expert committee. WHO, Geneva, Switzerland. 237 pp.

(WHO) World Health Organization. 2019. Trypanosomiasis, human African (sleeping sickness). 11 October 2019. 